Check for updates

Newcastle-upon-Tyne, UK

stokel@gmail.com

Cite this as: $B M J 2021 ; 372: n 99$

http://dx.doi.org/10.1136/bmj.n99

Published: 19 January 2021

\section{What we know about covid-19 reinfection so far}

\section{With most coronaviruses, recovery confers a degree of immunity to reinfection. But a small number of patients have caught covid-19 for a second time. Chris Stokel-Walker looks at what we know and how worried we should be}

Chris Stokel-Walker freelance journalist

\section{How often does reinfection occur?}

"Other things being equal, we can expect to see-even without this new variant (the UK-identified B117)-repeat infections by about now anyway," says Paul Hunter, professor in medicine at the University of East Anglia.

There are four types of endemic coronaviruses (229E, NL63, OC43, and HKU1) that regularly circulate through humans, causing the majority of respiratory tract infections. Infection with any of them can lead to immunity of differing lengths, typically lasting for at least a year or two, according to Joël Mossong, the head of epidemiology and microbial genomics at the Luxembourg National Health Authority. "You do get reinfected eventually, but not every year," he says.

But SARS-CoV-2 is an entirely new type of coronavirus and the question of immunity is one of the biggest unknowns. Whether infection confers immunity to reinfection "is uncertain," wrote Newcastle University academics in a paper published in the Journal of Infection in December 2020.

Of 11 ooo healthcare workers who had proved evidence of infection during the first wave of the pandemic in the UK between March and April 2020, none had symptomatic reinfection in the second wave of the virus between October and November 2020. As a result, the researchers felt confident that immunity to reinfection lasts at least six months in the case of the novel coronavirus, with further studies required to understand much more.

An early study by Public Health England, indicated that antibodies provide $83 \%$ protection against covid-19 reinfections over a five month period. Out of 6614 participants, 44 had "possible" or "probable" reinfections. $^{2}$

Worldwide, 31 confirmed cases of covid-19 reinfection have been recorded, although that could be an underestimate from delays in reporting and resource pressures in the ongoing pandemic.

"We know that reinfections with SARS-CoV-2 can happen," says Ashleigh Tuite, assistant professor at the University of Toronto's Dalla Lana School of Public Health. "The bigger question is: if reinfections are going to happen, how frequently are they happening?”

With attention focused on vaccine rollout and tracking the spread of new variants of covid-19, little work is being done to find out. "If they're happening a lot, but they're happening in the context of being less severe, we're not going to see them unless we design a study that actively tries to figure that out," says Tuite.

\section{Is disease from reinfection more severe?}

Since the 1960s, scientists have known that when some patients are infected with a virus for a second time, ${ }^{3}$ antibodies created to fend off the disease in the first instance can end up inadvertently compounding its effectiveness on reinfection-known as antibody dependent enhancement (ADE).

To date, most of the SARS-CoV-2 reinfections that have been reported have been milder than first encounters with the virus, although some have been more harmful-and two people have died as a result.

"Almost certainly, immunity from a mild infection doesn't last as long," said Hunter. "But on balance, most second infections are going to be a lot less severe because of a degree of immune memory and T cell mediation."

But Mossong says that, in his experience with coronaviruses, those who experience the mildest symptoms in their initial infection have a higher likelihood of reinfection, perhaps because they didn't develop an immune response the first time. The same goes for those who are immunosuppressed and therefore would not have mounted an immune response to the first infection either.

Then again, what those people are experiencing could be less a reinfection, and more a reactivation of pre-existing covid-19 within the body, reckons Mossong. That's far more difficult to ascertain.

\section{Reinfection or reactivation?}

To differentiate between what is a reinfection-from a new coronavirus entering the body-and what is an already extant coronavirus refiring the immune response is difficult because of sampling. It's only truly understandable if patients give samples during their first episode of illness that are then kept and sequenced genetically.

First, you'd need to obtain and then sequence a sample after the first episode and then obtain and sequence a second sample from the same patient (which had tested positive for covid-19). The genomes of the viruses from the two samples would need to be shown to be different for it to be a reinfection.

"With a genetic sequence, you can see whether it was the same variant or a different one," says Melvin Sanicas, a vaccinologist and member of the Royal Society of Tropical Medicine and Hygiene. Published papers have examined reinfections in Hong Kong 
using such methods. 4 "There was good evidence to show it wasn't the same," Sanicas adds.

But sequencing of this order is a tall ask, particularly with the stretched testing and laboratory resources of the current pandemic. "Even in the UK, which conducts sequencing of samples more regularly than most countries, only about $5-10 \%$ of samples are sequenced," says Mossong. "For that to occur twice, for samples from the same patient, the odds get smaller and smaller."

Research conducted at the Nuffield Department of Medicine at the University of Oxford purports that many of the cases of reinfection may actually be reactivation. ${ }^{5}$ Mossong points out that coronaviruses give long infections and their large genomic structures could cause them to remain in the body at low enough levels to remain undetected but ready to strike once more. "They could last longer in different parts of the body than respiratory areas," Mossong told The BMJ, pointing to persistent loss of smell and taste as possible evidence that the virus remains within the body, replicating at a low level, for a long time.

\section{What do the new variants mean for reinfection?}

SARS-CoV-2 variant B.117, first identified in the UK, has been shown to be more transmissible than previous variants, sparking a fresh wave of restrictions in the UK. But whether those who have already recovered from the virus are at risk is another unknown.

"I don't know how likely that is to increase the chance of reinfections," Hunter told The BMJ. He assumes that reinfections will be more likely with the new strain because of an absolute increase in the number of infections in general but hopes they will be less likely and less virulent than first infections.

Yet the emergence of a new SARS-CoV-2 variant, P.1, may throw that into question. A pre-print paper tracking the likelihood of being infected with the new variant, which emerged in Manaus, Brazil, in late 2020, indicates that it "eludes the human immune response" triggered by previous variants. Reinfection is therefore likely.

"The question is how much genetic drift or change can happen in the virus, such that your immune system doesn't recognise it anymore and doesn't mount a protective immune response," says Tuite, who spoke before the P.1 variant surfaced. Vaccine manufacturers have made assurances that their vaccines will stand up to the new B.117 variant, which according to Tuite suggests it hasn't changed enough to make people more prone to reinfection because of the virus itself. (Vaccine reactions can be different to natural immune responses, although it's too early to say what the differences are in the case of covid-19. Vaccine triggered immune responses are more consistent and could even be more powerful than those triggered naturally according to some studies. ${ }^{6}$ )

For now, the message is clear: "If you've recovered from SARS-CoV-2, it's not an excuse to forget about social distancing and not to wear a mask," says Sanicas, "We know that you can have it twice." And that means you can get it again and pass it on.

\section{Commissioned, not peer reviewed}

Competing interests: I have read and understood BMJ policy on declaration of interests and have no relevant interests to declare.

1 Hanrath AT, Payne BAI, Duncan CJA. Prior SARS-CoV-2 infection is associated with protection against symptomatic reinfection. J Infect. 2020 Dec 26;S0163-4453(20)30781-7. doi: 10.1016/j.jinf.2020.12.023.

2 Wilkinson E. Covid-19 reinfection "rare" says NHS study but some may still pass the virus on. Pulse. 2021. www.pulsetoday.co.uk/news/coronavirus/covid-19-reinfection-rare-says-nhs-studybut-some-may-still-pass-the-virus-on.
3 Halstead SB. Dengue hemorrhagic fever: two infections and antibody dependent enhancement, a brief history and personal memoir. Rev Cubana Med Trop 2002;54:171-9.pmid: 15846943

4 Parry J. Covid-19: Hong Kong scientists report first confirmed case of reinfection. BMJ 2020;370:m3340. doi: 10.1136/bmj.m3340 pmid: 32847834

5 Simmonds P, Williams S, Harvala H. Understanding the outcomes of COVID-19-does the current model of an acute respiratory infection really fit?/ Gen Virol 2020 . . doi: 10.1099/jgv.0.001545 pmid: 33331810

6 Widge AT, Rouphael NG, Jackson LA, et almRNA-1273 Study Group. Durability of responses after SARS-CoV-2 mRNA-1273 vaccination. N Engl J Med 2021;384:80-2. doi: 10.1056/NEJMc2032195 pmid: 33270381 